\title{
Submerged membrane filtration adsorption hybrid system for the removal of organic micropollutants from a water reclamation plant reverse osmosis concentrate
}

Sukanyah Shanmuganathan ${ }^{1}$, Paripurnanda Loganathan ${ }^{1}$, Christian Kazner ${ }^{2}$, M.A.H. Johir ${ }^{1}$ Saravanamuthu Vigneswaran ${ }^{1,3}$

${ }^{1}$ University of Technology Sydney, School of Civil and Environmental Engineering, PO Box 123, Broadway, NSW 2007, Australia

${ }^{2}$ University of Applied Sciences and Arts of Northwestern Switzerland, School of Life Sciences, Institute of Ecopreneurship, Gründenstrasse 40, CH-4132 Muttenz, Switzerland

${ }^{3}$ Corresponding author: s.vigneswaran@uts.edu.au, Tel.: 6129514 2641; Fax: 6129514 2633

\section{Research highlights}

- A water treatment plant RO concentrate had 19 organic micropollutants (OMP).

- Submerged membrane filtration GAC adsorption removed all OMP to <detection limits.

- This hybrid system helps to produce additional amounts of nutrient-rich water.

\begin{abstract}
Reverse osmosis (RO) is a widespread water treatment process utilised in water reuse applications. However, the improper discharge of RO concentrate (ROC) containing organic
\end{abstract}


micropollutants such as pharmaceuticals into the environment may cause potential health risks to non-target species and particularly those in aquatic environments. A study was conducted using a submerged membrane-filtration/granular activated carbon (GAC) adsorption hybrid system to remove organic micropollutants from a water treatment plant ROC by initially adding $10 \mathrm{~g}$ GAC /L of membrane reactor volume with $10 \%$ daily GAC replacement. The percentage of dissolved organic carbon removal varied from $60 \%$ to $80 \%$ over an operation lasting $10 \mathrm{~d}$. Removal of organic micropollutants was almost complete for virtually all compounds. Of the 19 micropollutants tested, only two remained (the less hydrophobic DEET $27 \mathrm{ng} / \mathrm{L}$ and the hydrophilic sulfamethoxazole $35 \mathrm{ng} / \mathrm{L}$ ) below $80 \%$ removal on day 1 , while five of the most hydrophobic micropollutants were detectable in very small concentrations $(<5-10 \mathrm{ng} / \mathrm{L})$ with $>89 \%$ - > 99\% being removed. High percentages of micropollutants were removed probably because of their high hydrophobicity or they had positive or neutral charges and therefore they were electrostatically adsorbed to the negatively charged GAC.

Keywords: adsorption: granular activated carbon; micropollutants; reverse osmosis concentrate; submerged membrane filtration.

\section{Introduction}

Inadequate clean water for potable and non-potable use has become a major problem worldwide due to the increasing demand and shortage of water resources. Water recycling by treating wastewater is a useful approach to alleviate this problem. However, wastewater contains many contaminants which need to be removed before it can be beneficially utilised. In this context, membrane technology is currently growing at a great rate due to its excellent ability to remove contaminants and smaller foot-print requiring less space compared to 
conventional treatment technologies. Of the different types of membrane filtration, reverse osmosis (RO) is widely used in water reuse applications due to its greater efficiency in removing contaminants including organic micropollutants, for example pharmaceuticals and personal care products (PPCPs), insecticides, surfactants, endocrine disruptors, and hormones [1]. However, the rejected micropollutants are discharged normally into surface water bodies with the RO concentrate (ROC). The improper discharge of organic micropollutants with the ROC into the environment may cause potential health risks to non-target species particularly in aquatic environments [2]. Subsequently, the application of proper treatment techniques is essential to ensure safe disposal of ROC free of organic micropollutants into the natural environment.

The concentration of various organic micropollutants in Australian waters is summarised in Table 1. These contaminants are commonly found at trace levels in the environment ranging from nanogram to microgram per litre $(\mathrm{ng} / \mathrm{L}-\mu \mathrm{g} / \mathrm{L})$ and as such are also known as trace organics. Wastewater treatment plants (WWTPs) constitute the major sources that continuously release organic micropollutants into water bodies [3-5] and it is now well known that organic micropollutants are ubiquitous contaminants in WWTP effluents [4]. Generally, during primary treatment, many of these pollutants are mainly removed by adsorption onto the sludge produced [6], but the amounts of some of them that are removed, such as naproxen, and sulfamethoxazole, are insignificant [7]. Secondary treatment can remove the organic micropollutants via biodegradation, biotransformation and adsorption [8]. However, concentrations of some of them such as sulfamethoxazole and sulfapyridine might increase in the effluent compared to those in the influent due to their transformation back into the parent compounds [9]. Thus, the possibility of detecting organic micropollutants in the effluent of WWTP is inevitable because: firstly, most of the WWTPs in operation are not specially designed to remove these pollutants completely; and secondly, no monitoring 
actions/precautions for micropollutants have been defined [10]. 
Table 1. Concentrations of organic micropollutants in Australian waters [11]

\begin{tabular}{lll}
\hline Compounds & WWTP effluent $(\mathrm{ng} / \mathrm{L})$ & Freshwater, rivers, canals \\
\hline Trimethoprim & $58-321$ & $4-150$ \\
Ciprofloxacin & $42-720$ & $23-1300$ \\
Sulfamethoxazole & $3.8-1400$ & $1.7-2000$ \\
Naproxen & $128-548$ & $11-181$ \\
Ibuprofen & $65-1758$ & $28-360$ \\
Ketoprofen & - & $<0.4-79.6$ \\
Diclofenac & $8.8-127$ & $1.1-6.8$ \\
Carbamazepine & $152-226$ & $25-34.7$ \\
Propranolol & 50 & - \\
Gemfibrozil & $3.9-17$ & $1.8-9.1$ \\
\hline
\end{tabular}

Several treatment technologies have been applied to remove organics from ROC such as coagulation-flocculation processes and advanced oxidation processes, namely ozonation, Fenton process, photocatalysis and photo-oxidation, sonolysis, and electro-chemical oxidation. Many studies have found that adsorption of organic micropollutants onto activated carbon either in the form of powdered activated carbon (PAC) or granular activated carbon (GAC) is a simple and very efficient technique $[1,12]$. This is particularly so when comparing it to coagulation-flocculation processes [13] and ozone oxidation [14].

Some studies investigated a combined PAC-ultrafiltration (UF) system in the tertiary treatment phase to remove organic micropollutants along with a coagulation treatment phase $[14,15]$. This combination emerged as the most suitable one because the effective removal of contaminants occurred without forming problematic by-products [14]. Löwenberg et al. [15] studied the PAC/UF system to remove five organic micropollutants, specifically sulfamethoxazole, carbamazepine, mecoprop, diclofenac and benzotriazole from a wastewater effluent (DOC $8.8 \pm 1.2 \mathrm{mg} / \mathrm{L}$ ). They reported that a PAC dose of $20 \mathrm{mg} / \mathrm{L}$ was enough to remove $60-95 \%$ of the micropollutants. Margot et al. [14] studied the removal of 70 organic micropollutants from wastewater effluent (DOC $7.3 \pm 1.9 \mathrm{mg} / \mathrm{L}$ ) in which on average more than $70 \%$ of them were removed at an average dose of $13 \mathrm{mg} / \mathrm{L}$ of PAC. In addition to the 
removal of micropollutants, the PAC can reduce membrane fouling by adsorbing dissolved bulk organics which are the major fouling agents. In these treatment systems the PAC adsorption and membrane filtration (MF) were carried out separately one after the other.

Vigneswaran et al. [16] studied the combined/hybridised form of carbon adsorption and MF together in a single stage of treatment for the removal of dissolved organics. In addition to carbon adsorption of the organics, this configuration was observed to be effective in terms of fouling reduction due to the membrane scouring effect. The direct contact of carbon particles with membrane surface can produce mechanical scouring effect by means of physical abrasion. This may mitigate the accumulation of foulants on top of the membrane surface and subsequently reduce build-up of transmembrane pressure (TMP). These two advantages of the submerged MF adsorption hybrid system are believed to reduce the membrane fouling further, and as such the operation can be extended for the long-term. Furthermore the frequency of membrane cleanings can be minimised.

In some membrane adsorption hybrid system studies, PAC was used as the suspended adsorbent to remove organics [17-20]. In these studies the removal of organics was observed to increase when the PAC dosage rose. However, the high concentration of PAC dose formed a PAC cake on the membrane surface and consequently the flux declined. Guo et al. [21] reported that the initial PAC dose of $1 \mathrm{~g} / \mathrm{L}$ was effective in a membrane-adsorption hybrid system in terms of organics removal and stable filtration flux, whilst the increase of initial PAC dose to $5 \mathrm{~g} / \mathrm{L}$ dropped the filtration flux rapidly due to cake development. It should be noted that in the above study, only the initial dose was $5 \mathrm{~g} / \mathrm{L}$ of reactor, and only $5 \mathrm{mg}$ PAC/L of the reactor was added (or replaced) on a daily basis which corresponded to less than $25 \mathrm{mg}$ PAC/L dose. 
Using larger particle size of activated carbon would be better than smaller ones due to the greater membrane scouring effect and higher fouling reduction [22]. Kim et al. [18] reported that the use of GAC along with MF reduced the TMP development and frequency of chemical cleaning by half. Pradhan et al. [23] concluded that adding GAC to MF not only provided mechanical scouring but also helped to reduce air scour. Another analysis noted that an increase in the particle size of Purolite A502PS significantly reduced TMP while maintaining low membrane fouling [24].

Only a few studies have been conducted on the use of PAC or GAC/MF hybrid system for the removal of organic micropollutants. Löwenberg et al. [15] investigated the efficiency of removing only five organic micropollutants from municipal wastewater treatment plant effluent using a pressurised PAC/UF system and a submerged PAC/UF system. They found that the latter system removed slightly larger amounts of organic pollutants compared to the former system. Shanmuganathan et al. [25,26] reported that a GAC/MF system was very effective in removing most of the 9 and 17 organic micropollutants tested in a biologically treated sewage effluent [25] and ROC [26], respectively. However, the previous study on ROC was only of a short-term duration lasting $6 \mathrm{~h} \mathrm{[26].}$

The aim of this study was to examine the feasibility of using the GAC/MF hybrid system as a long-term $(10 \mathrm{~d})$ continuous treatment option with daily replacement of GAC to achieve superior removal of organic micropollutants from ROC. The mechanisms for removing 19 micropollutants were evaluated by considering electric charges and hydrophobicity values obtained from chemical software that are more accurate than the previously used values obtained from equations. In addition to the removal of organic micropollutants and DOC, the GAC can also provide scouring to the membrane surface, and consequently reduce membrane fouling. 


\section{Materials and methods}

2.1. Materials

\subsubsection{Reverse osmosis concentrate}

Reverse osmosis concentrate (ROC) collected from an advanced water treatment plant in Sydney, Australia treating secondary effluent was used as feed water. The plant process consists of both continuous flow microfiltration (CMF) and reverse osmosis to treat the biologically treated effluent. The RO units produced a ROC which contained all the contaminants rejected by RO. The water quality characteristics of the ROC are presented in Table 2. 
Table 2. Characteristics of ROC

\begin{tabular}{lll}
\hline Parameters & Unit & Value \\
\hline $\mathrm{pH}$ & & $7.4-7.6$ \\
Conductivity & $\mu \mathrm{S} / \mathrm{cm}$ & $2500-3500$ \\
$\mathrm{DOC}$ & $\mathrm{mg} / \mathrm{L}$ & $20-30$ \\
$\mathrm{~F}^{-}$ & $\mathrm{mg} / \mathrm{L}$ & $3.5-7.7$ \\
$\mathrm{Cl}^{-}$ & $\mathrm{mg} / \mathrm{L}$ & $600-900$ \\
$\mathrm{NO}_{3}{ }^{-}$ & $\mathrm{mg} \mathrm{N} / \mathrm{L}$ & $22-40$ \\
$\mathrm{PO}_{4}{ }^{3-}$ & $\mathrm{mg} \mathrm{P} / \mathrm{L}$ & $9-15$ \\
$\mathrm{SO}_{4}{ }^{2-}$ & $\mathrm{mg} \mathrm{S} / \mathrm{L}$ & $180-300$ \\
$\mathrm{Na}^{+}$ & $\mathrm{mg} / \mathrm{L}$ & $373-540$ \\
$\mathrm{~K}^{+}$ & $\mathrm{mg} / \mathrm{L}$ & $64-120$ \\
$\mathrm{Ca}^{2+}$ & $\mathrm{mg} / \mathrm{L}$ & $95-200$ \\
$\mathrm{Mg}^{2+}$ & $\mathrm{mg} / \mathrm{L}$ & $45-80$ \\
\hline
\end{tabular}

\subsubsection{Granular activated carbon}

A coal-based premium grade (MDW4050CB) GAC obtained from James Cumming and Sons Pty. Ltd. served in this study as an adsorbent. Three different sizes of GAC (150$300 \mu \mathrm{m}, 300-600 \mu \mathrm{m}$, and $600-1200 \mu \mathrm{m}$ ) were tested and the GAC size of 300-600 $\mu \mathrm{m}$ was found to be suitable. It had an iodine number $1000 \mathrm{mg} / \mathrm{g}$, BET surface area $750 \mathrm{~m}^{2} / \mathrm{g}$, and average pore diameter $30 \AA$

\subsubsection{Membranes}

A hollow fibre MF membrane (Mann+Hummel Ultra-Flo Pte Ltd, Singapore) consisting of hydrophilic modified polyacrylonitrile (PAN) was used in the submerged MFGAC hybrid system. The surface area of the MF membrane was $0.044 \mathrm{~m}^{2}$ and pore size was $0.10 \mu \mathrm{m}$.

\subsection{Experimental methods}




\subsubsection{Zeta potential of GAC}

Zeta potential is the electrical potential near a particle surface where adsorption of ions or ionic compounds from solution takes place and is related to the surface charge. The higher the negative zeta potential value the higher the amount of adsorption of positively charged micropollutants and vice-versa. Suspensions of $1 \mathrm{mg} / \mathrm{L}$ GAC in deionised water were prepared and the $\mathrm{pH}$ was adjusted from 3.0 to 10 , utilising $0.1 \mathrm{M} \mathrm{NaOH}$ or $0.1 \mathrm{M} \mathrm{HNO}_{3}$ solutions using a HQ40d portable $\mathrm{pH}$ Meter. The suspensions were agitated for $24 \mathrm{~h}$ in a flat shaker at a shaking speed of $120 \mathrm{rpm}$ at room temperature $\left(24 \pm 1^{\circ} \mathrm{C}\right)$. Zeta potential was measured using a Zetasizer nano instrument (Nano ZS Zen3600, Malvern, UK) after measuring the final $\mathrm{pH}$.

\subsubsection{Submerged MF-GAC adsorption hybrid system}

The submerged MF-GAC adsorption hybrid system in this study was primarily used to improve the removals of DOC and micropollutants from feed water in which the contaminants were removed by adsorption onto GAC, and this was followed by membrane filtration. The MF membrane itself does not have the ability to remove DOC and micropollutants since the membrane's pore size is much larger than those of the contaminants. The role of the GAC was to adsorb organics as well as micropollutants from the feed water while that of the MF was to retain the GAC particles and organics-adsorbed-GAC. In a submerged MF-GAC adsorption experiment with and without GAC it emerged that MF filtration alone removed less than $10 \%$ DOC but when a daily GAC replacement of $0.5 \mathrm{~g} / \mathrm{L}$ of membrane reactor was added, the percentage of DOC removed rose to $20-60 \%$ [26]. DOC removal further increased to $65-90 \%$ with the daily addition of GAC of $2 \mathrm{~g} / \mathrm{L}$. The inability to remove significant amounts of DOC by MF alone was explained as being due to the larger pore size of the membrane. 
Figure 1, a low pressure MF membrane module was submerged in the reactor containing $3 \mathrm{~L}$ of raw ROC. Two Master flux pumps were used to pump raw ROC into the reactor and to pump effluent out of the reactor. The flux of influent and effluent had the same settings in order to maintain a constant water level in the reactor. A pressure gauge (Novus $\log$ box) was employed to measure the transmembrane pressure (TMP) of the submerged MF-GAC adsorption hybrid system.

A GAC dose of $10 \mathrm{~g} / \mathrm{L}$ was added into the reactor at the beginning of the experiment to reduce organic loading to the membrane. Following this, $10 \%$ of GAC in the reactor was replaced with new GAC on a daily basis. The dose of $10 \mathrm{~g} / \mathrm{L}$ GAC was chosen based on previous studies and our preliminary experiments as explained below. Vigneswaran et al. [20] showed that the increase in PAC dose from $2 \mathrm{~g} / \mathrm{L}$ to $10 \mathrm{~g} / \mathrm{L}$ in a MF-PAC increased DOC removal only marginally from $83.4 \%$ to $87.5 \%$ in synthetic wastewater (DOC $3.8-4.2 \mathrm{mg} / \mathrm{L}$ ). Our short-term MF-GAC experiments conducted on ROC with GAC doses 5, 10 and $20 \mathrm{~g} / \mathrm{L}$ removed $20-50 \%, 60-80 \%$, and, $70-90 \%$ of DOC, respectively, over a $4 \mathrm{~h}$ operation. This corresponds to average effluent DOC levels of $13.3,4.7$ and $3.5 \mathrm{mg} / \mathrm{L}$, respectively. Considering minimum carbon usage to cut down cost and producing satisfactory DOC removal, an initial GAC dose of $10 \mathrm{~g} / \mathrm{L}$ with $10 \%$ daily replacement was selected for this long-term experiment. The daily replacement of GAC is equivalent to a GAC dose of $0.28 \mathrm{~g}$ of GAC/L treated-water/day. This is comparable to the PAC dose of $0.42-0.48 \mathrm{~g} / \mathrm{L}$ estimated by Wang et al. [27] to achieve 70\% removal of DOC (approximately $12-13 \mathrm{mg} / \mathrm{L} \mathrm{DOC}$ in the effluent) from ROC by a single stage PAC-UF treatment system. The daily GAC replacement dose $(0.28 \mathrm{~g} / \mathrm{L})$ used in this study was low compared to the one used by Wang et al. [27] for similar or smaller DOC removals (i.e. 50-80\% DOC removal; effluent DOC level was 5-10 $\mathrm{mg} / \mathrm{L})$. The higher initial dose of GAC was deliberately used to: firstly, improve the contaminant removals (both DOCs and micropollutants); and secondly, reduce TMP 
development. The GAC dose was high compared to that used in water treatment plants because the DOC content in ROC was much higher than the amount found in surface waters.

The flux was maintained at $10 \mathrm{~L} / \mathrm{m}^{2}+\mathrm{h}$ which corresponded to a retention time of 410 min or about $7 \mathrm{~h}$. This particular flux and retention time was chosen based on batch kinetics where the maximum removal of DOC was up to $80 \%$ at a GAC dose of $2 \mathrm{~g} / \mathrm{L}$ in $410-420 \mathrm{~min}$. An air diffuser served to maintain a constant airflow to produce shear stress on the membrane's surface as well as to keep the GAC particles in suspension in the reactor tank. The loss of volatile organic compounds (VOCs) due to aeration was neglected as the wastewater used in this study was previously biologically treated and hence well stabilised. The experiment was continued for $10 \mathrm{~d}$.

\subsubsection{Sampling}

One litre effluent samples were collected daily to measure effluent DOC. Samples collected on day 1 and day 7 were also used for the measurement of micropollutants concentrations. Influent concentration of micropollutants was also measured. Samples collected after day 7 were not analysed for micropollutants because all the $7^{\text {th }}$ day samples contained micropollutants below the detection limits. 


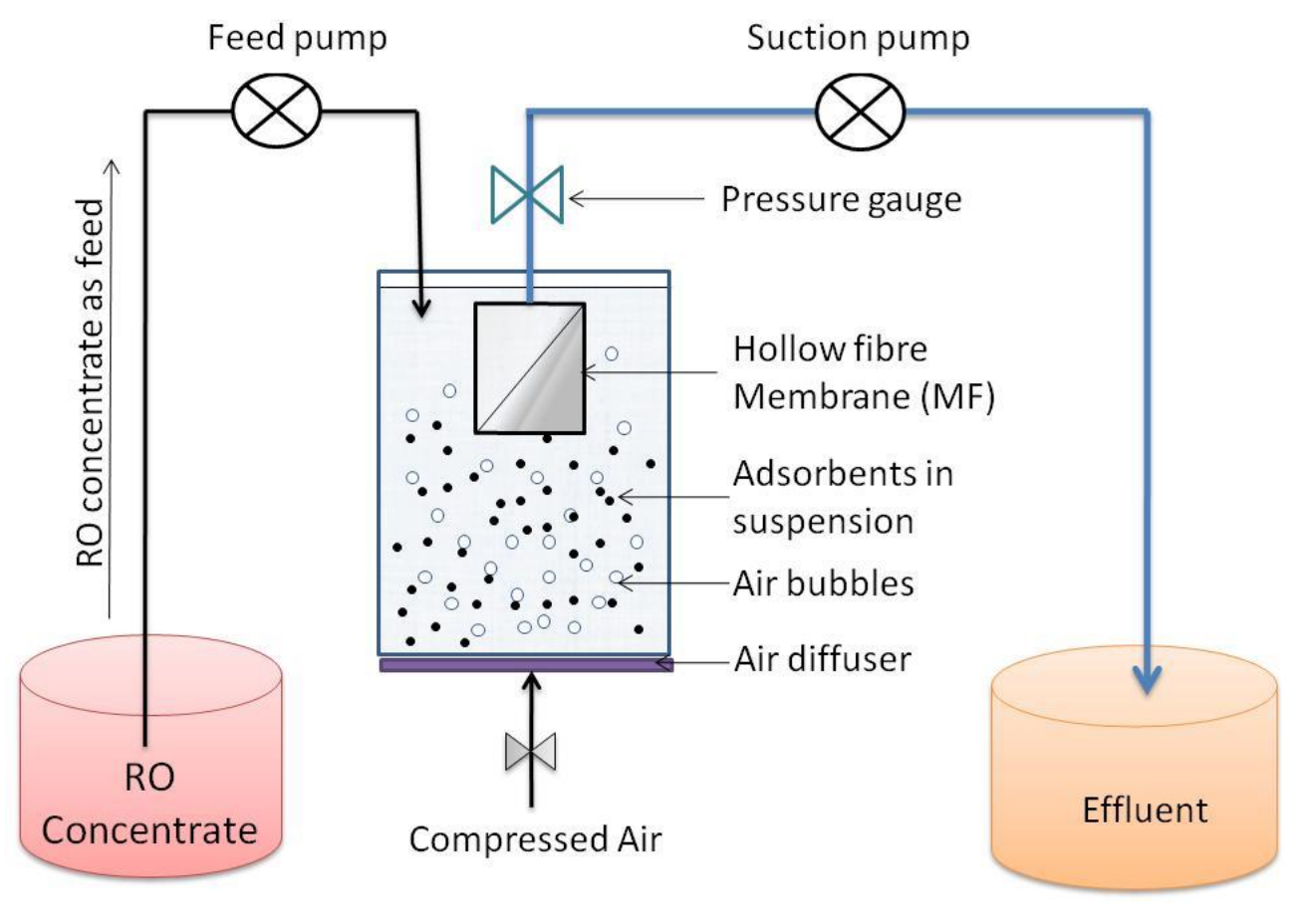

Figure 1. Schematic diagram of the submerged MF-GAC adsorption hybrid system

\subsection{Analytical methods}

\subsubsection{Dissolved organics}

The DOC of the samples was analysed using a Multi N/C 2000 TOC analyser after filtering samples through a filter paper with $0.45 \mu \mathrm{m}$ opening. The samples were injected using an auto sampler and then automatically analysed for total carbon (TC) and inorganic carbon (IC). The DOC was calculated by subtracting IC from TC. The calibration curve was regularly checked using standard glucose solutions.

\subsubsection{Micropollutants}

Micropollutants which include pharmaceuticals, personal care products and pesticides were extracted using solid phase extraction (SPE) and analysed by Liquid Chromatograph with tandem mass spectroscopy. $5 \mathrm{~mL}$ analytes were extracted using $500 \mathrm{mg}$ hydrophilic/lipophilic balance (HLB) cartridges (Waters, Milford, MA, USA). These analytes 
were separated using an Agilent (Palo Alto, CA, USA) 1200 series high performance liquid chromatography (HPLC) system equipped with a 150 x $4.6 \mathrm{~mm}, 5 \mu \mathrm{m}$ particle size, Luna C18 (2) column (Phenomenex, Torrance, CA, USA). Mass spectrometry was conducted using an API 4000 triple quadrupole mass spectrometer (Applied Biosystem, Foster City, CA, USA) equipped with a turbo- $\mathrm{V}$ ion source employed in both positive and negative electro-spray modes. All calibration curves had a correlation coefficient of 0.99 or better. Details of the analysis are described elsewhere [28].

\section{Results and Discussion}

\subsection{Characterisation of ROC in terms of DOC and micropollutants}

The ROC used in this study contained high concentrations of DOC (24 mg/L). Out of 31 different micropollutants measured in the feed water, 12 compounds were not detected above the limit of quantification (LOQ which ranged 5-20 ng/L). The undetected compounds were diazepam (anti-convulsant), diazinon (insecticide), enalpril (enzyme inhibitor), hydroxyzine (therapeutic), ibuprofen (analgesics), linuron (herbicide), meprobamate (therapeutic), omeprazole (therapeutic), phenylphenol (agricultural chemical), risperidone (therapeutic), simvastatin (therapeutic), and t-octylphenol (surface active agent). Consequently these compounds are not discussed here. The concentrations of the micropollutants that were detected above the LOQ are documented in 
Table 3 However, most of the detected micropollutants in the ROC were below the predicted critical environmental concentrations (CEC), these being based on literature data on human potencies together with a predicted bio-concentration factor in fish for each drug based on lipophilicity [29].

Many of the micropollutants such as carbamazepine (2240 ng/L), caffeine (1410 ng/L), trimethoprim (974 ng/L), atenolol (466 ng/L), and naproxen (443 ng/L) were detected at high concentrations in feed water, yet these values are below their respective CECs. In comparison, the concentration of the PPCP, verapamil which is a cardiovascular agent was as low as $83 \mathrm{ng} / \mathrm{L}$ but this concentration exceeded its CEC (24 ng/L). The concentration of amtriptyline which is a neurotransmitter was $45 \mathrm{ng} / \mathrm{L}$ and this tends to approach its CEC (48 $\mathrm{ng} / \mathrm{L})$. Similarly, simvastatin which is a lipid regulator had a concentration $<5 \mathrm{ng} / \mathrm{L}$, however, its CEC was reported to be $6.1 \mathrm{ng} / \mathrm{L}$.

The CECs values reported by Fick et al. [29] utilised to assess the toxicity potentials of the micropollutants in ROC were derived from single compound-single organism toxicity studies. However, the combined and continuous exposure of micropollutants can cause chronic and dangerous toxic outcomes for aquatic organisms at concentrations below the CEC of individual micropollutants [30,31]. For example, Cleuvers [32] reported that the $\mathrm{EC}_{50}$ of diclofenac on algal and Daphnia test organisms were $71.9 \mathrm{mg} / \mathrm{L}$ and $68.0 \mathrm{mg} / \mathrm{L}$, respectively. These $\mathrm{EC}_{50}$ values fell to 18.0 and $17.0 \mathrm{mg} / \mathrm{L}$ when these species were exposed to combined micropollutants (diclofenac, ibuprofen, naproxen, acetylsalicylic acid). Therefore, even though most of the micropollutants detected in ROC were below their CECs in the current study, combinations of such compounds are likely to be very toxic to aquatic organisms when they are continuously exposed to this water, especially for a prolonged period of time. 
Table 3. Concentrations of micropollutants detected in ROC and their relevant properties

\begin{tabular}{|c|c|c|c|c|c|c|c|}
\hline Micropollutants & Class & $\begin{array}{l}M^{a} W^{a} \\
(g)\end{array}$ & $\begin{array}{l}\text { Charge }^{b} \\
\text { (pH 7.5) }\end{array}$ & Conc (ng/L) & $\begin{array}{l}\log D^{b} \\
(p H 7)\end{array}$ & $\begin{array}{l}\operatorname{Log~Kow}^{\mathrm{a}} \\
\text { (pH 7) }\end{array}$ & pKa \\
\hline Amtriptyline & Anti-depressant & 277 & + & 45 & 3.48 & 4.92 & $9.4^{\mathrm{a}}$ \\
\hline Atenolol & Beta-blocker & 266 & + & 466 & -1.87 & 0.16 & $9.6^{\mathrm{f}}$ \\
\hline Caffeine & Stimulant & 194 & 0 & 1410 & -0.11 & -0.07 & $10.4^{\mathrm{e}}$ \\
\hline Carbamazepine & Anti-analgesics & 236 & 0 & 2240 & 2.23 & 2.45 & $<1^{\mathrm{c}},<2^{\mathrm{d}}$ \\
\hline Clozapine & Antipsychotic agent & 327 & + & 68 & 2.63 & 3.23 & $7.5^{\mathrm{a}}$ \\
\hline DEET & Insect repellent & 191 & 0 & 68 & 2.46 & 2.18 & $<2^{\mathrm{d}}$ \\
\hline Diclofenac & Analgesics & 294 & - & 337 & 1.48 & 4.51 & $4.1-4.2^{c}$ \\
\hline Fluoxetine & Anti-depressant & 309 & + & 47 & 2.6 & 4.05 & $10.1^{\mathrm{c}}$ \\
\hline Gemfibrozil & Lipid regulator & 250 & - & 344 & 1.26 & 4.77 & $4.7^{\mathrm{d}}$ \\
\hline Ketoprofen & Analgesics & 254 & - & 377 & -0.14 & 3.12 & $4.45^{\mathrm{a}}$ \\
\hline Naproxen & Analgesics & 230 & - & 443 & 0.16 & 3.18 & $4.2^{\mathrm{c}} ; 4.15^{\mathrm{a}}$ \\
\hline Paracetamol & Analgesics & 151 & 0 & 114 & 0.54 & 0.46 & $9.38^{\mathrm{a}}$ \\
\hline Primidone & therapeutic & 218 & 0 & 26 & 0.55 & 0.91 & $11.7^{\mathrm{b}}$ \\
\hline Simazine & Herbicide & 202 & 0 & 80 & 2.2 & 2.18 & $1.62^{\mathrm{a}}$ \\
\hline Sulfamethoxazole & Therapeutic & 253 & - & 144 & -0.77 & 0.89 & $2.1^{\mathrm{d}} ;<2^{\mathrm{d}}$ \\
\hline Triclocarban & Agricultural chemical & 316 & 0 & 162 & 5.06 & 4.9 & $12.7^{\mathrm{g}}$ \\
\hline Triclosan & Anti-infective & 290 & 0 & 211 & 5.19 & 4.76 & $7.9^{\mathrm{c}}$ \\
\hline Trimethoprim & Anti-infective & 290 & 0 & 974 & 0.94 & 0.91 & $6.6-7.2^{c}$ \\
\hline Verapamil & Therapeutic agent & 455 & + & 83 & 2.97 & 3.79 & $8.92^{\mathrm{a}}$ \\
\hline
\end{tabular}

${ }^{\mathrm{a} U}$ US. National Library of Medicine (http://chem.sis.nlm.nih.gov/chemidplus/rn/52-53-9); ${ }^{\mathrm{b} C a l c u l a t e d ~ w i t h ~ A d v a n c e d ~ C h e m i s t r y ~ D e v e l o p m e n t ~}$ (ACD/Labs) Software V9.04 for Solaris; ' Serrano et al. [33]; ${ }^{\mathrm{d}}$ Westerhoff et al. [12]; ${ }^{\mathrm{e}}$ Yang et al. [34]; fHapeshi et al. [35]; ${ }^{\mathrm{g}} \mathrm{Loftsson}$ et al. [36]; MW: molecular weight 


\subsection{Zeta potential of GAC}

Zeta potentials of GAC were $+18.0,+13.2,+7.8,-11.6,-16.9$ and $-28.9 \mathrm{mV}$ at the final suspension pHs of $3.12,3.57,4.80,6.24,6.64$ and 8.00 , respectively. A plot of zeta potential vs $\mathrm{pH}$ revealed that the zero point of charge ( $\mathrm{ZPC}, \mathrm{pH}$ at which zeta potential is zero) of GAC tested was 5.5, indicating that the net surface charge on GAC particles at the ROC $\mathrm{pH}$ of 7.5 was negative. Therefore, the positively charged micropollutants are expected to be removed more easily than the negatively charged ones by electrostatic adsorption onto the GAC.

\subsection{Submerged MF-GAC adsorption hybrid system}

\subsubsection{DOC removal and TMP development}

The MF-GAC adsorption hybrid treatment system was tested on a long-term basis. This study complements our short-term study $(6 \mathrm{~h})$ conducted using a GAC/MF hybrid system with two different GAC doses ( 5 and $20 \mathrm{~g} / \mathrm{L}$ of membrane reactor volume) at a high flux $\left(36 \mathrm{~L} / \mathrm{m}^{2} \mathrm{~h}\right)$ [26]. In that study, the application of GAC doses of $5 \mathrm{~g} / \mathrm{L}$ and $20 \mathrm{~g} / \mathrm{L}$ removed $45 \%$ and $86 \%$ of DOC, respectively and reduced TMP development from $25 \mathrm{KPa}$ (no GAC addition) to $15 \mathrm{KPa}$.

In this study, the initial dose of $10 \mathrm{~g} / \mathrm{L} \mathrm{GAC}$ was put into the reactor to reduce the direct organic load onto the membrane by adsorption of the DOC onto GAC so that any TMP development could be circumvented. At day 1, the DOC removal was $80 \%$ but after $4-6 \mathrm{~d}$ of operation it declined and was maintained at 50-60\%. In our short-term experiment a similar decline in percentage in terms of DOC removed was observed [26]. Although the total amount of retained DOC increased, the percentage removed declined probably because initially the DOC constituents having higher affinity to GAC (constituents having high 
hydrophobicity and positive/neutral charges) were adsorbed, leaving the constituents with lower affinity in solution. At the $\mathrm{pH}$ of the ROC (pH 7.5), GAC is negatively charged (see zeta potential data) and therefore has high affinity to positively charged DOC species. GAC is also shown to have high affinity to hydrophobic compounds [37].

A continuous removal of DOC led to a TMP increase from $10 \mathrm{kPa}$ to $60 \mathrm{kPa}$ over the $9 \mathrm{~d}$ (Figure 2). The amount of ROC treated per day by $3 \mathrm{~g}$ of replaced GAC was $10.5 \mathrm{~L}$. This corresponds to a GAC dose of $0.28 \mathrm{~kg} / \mathrm{m}^{3}$ of ROC treated.

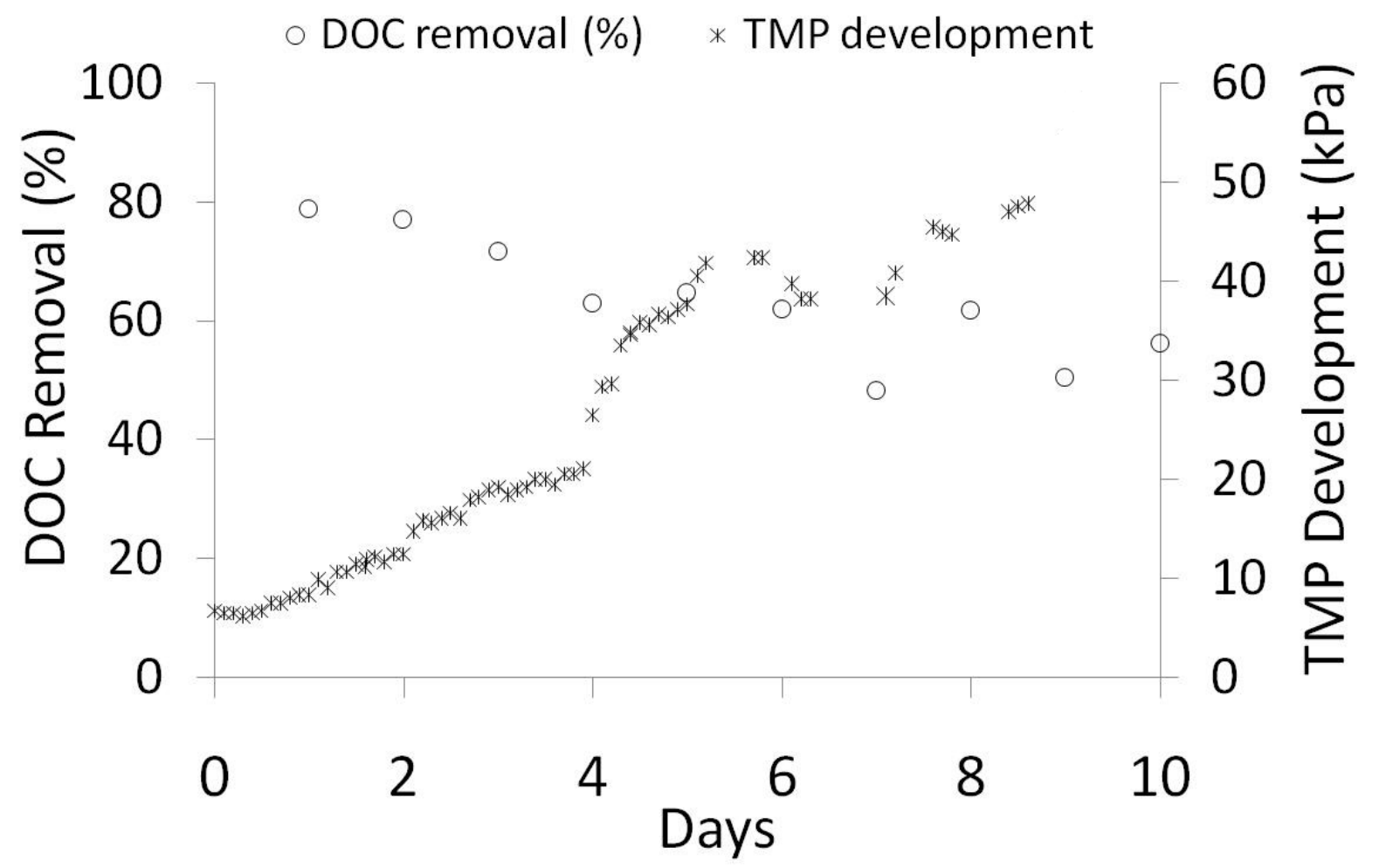

Figure 2. DOC removal efficiency and TMP development in the long-term submerged MFGAC hybrid system used in treating ROC $\left[\right.$ Flux $=10 \mathrm{~L} / \mathrm{m}^{2}+\mathrm{h}$; Initial GAC dose $=10 \mathrm{~g} / \mathrm{L}$ with $10 \%$ GAC daily replacement].

\subsubsection{Removal of micropollutants by MF-GAC}

Overall, MF-GAC removed $60 \%$ - >99\% of micropollutants from ROC in which it 
was noticed that the removals were generally higher at day $7(>81->99 \%)$ than at day $1(60$ $>99 \%$ ) (Table 4). The percentages removed on day 1 are similar to those reported earlier by us $(65 \%$ - >89\%) in a short-term study $(6 \mathrm{~h})$ for a GAC dose of $5 \mathrm{~g} / \mathrm{L}$; the removal percentages increased to $>81 \%$ - $100 \%$ for a GAC dose of $20 \mathrm{~g} / \mathrm{L}$ [26]. In another study [25], the percentages of removed micropollutants were reported to be lower $(27.7 \%$ - $>79.2 \%)$ for a smaller GAC dose of $2 \mathrm{~g} / \mathrm{L}$ with daily replacement of $5 \%$ GAC. This was even after $14 \mathrm{~d}$ for the same flux of $10 \mathrm{~L} / \mathrm{m}^{2} \mathrm{~h}$ as shown in this study.

The hydrophilic or less hydrophobic DEET and sulfamethoxazole were removed at only at $60 \%$ and $76 \%$, respectively, at day 1 but all other micropollutants were removed at > 81\% (Table 4). At day 7, all micropollutants including DEET and sulfamethoxazole were removed at $>81-99 \%$ with concentrations below the detection limits. The marked increase in removal of many of the micropollutants over time despite a decrease in percentage of DOC removed, indicates that initially the DOC constituents with high affinity to GAC were removed. As time progressed the concentration of low affinity DOC constituents in solution increased at a higher rate than the high affinity constituents. This allowed a larger percentage of micropollutants to be adsorbed. The molecular weights and thus the size of micropollutants are much smaller than those of most bulk organics. Therefore, the micropollutants might have diffused into the fine pores of GAC (micropores) and become adsorbed whereas the bulk organics would have adsorbed onto the surface and mesopores/macropores [38]. Since diffusion process is slow because of pore blockage by DOC causing diffusion tortuosity [38], several days may have passed for the adsorptive removal of micropollutants inside the pores to occur. Although the percentages of micropollutants removed were higher than those of DOC, the absolute amounts removed were much lower because the DOC concentrations were much higher than those of micropollutants (> 1000 times those of micropollutants, see Tables 2 and 3). 
Table 4. The removal of micropollutants by the MF-GAC hybrid system from ROC

\begin{tabular}{|c|c|c|c|c|c|}
\hline \multirow[t]{2}{*}{ Micropollutants } & \multirow{2}{*}{ Influent (ng/L) } & \multicolumn{2}{|c|}{ Effluent (ng/L) } & \multicolumn{2}{|c|}{ Removal (\%) } \\
\hline & & Day 1 & Day 7 & Day 1 & Day 7 \\
\hline Amtriptyline & 45 & $<5$ & $<5$ & $>89$ & $>89$ \\
\hline Atenolol & 466 & $<5$ & $<5$ & $>99$ & $>99$ \\
\hline Caffeine & 1410 & 31 & $<5$ & 98 & $>99$ \\
\hline Carbamazepine & 2240 & 86 & $<5$ & 96 & $>99$ \\
\hline Clozapine & 68 & $<5$ & $<5$ & $>93$ & $>93$ \\
\hline DEET & 68 & 27 & $<5$ & 60 & $>93$ \\
\hline Diclofenac & 337 & $<5$ & $<5$ & $>99$ & $>99$ \\
\hline Fluoxetine & 47 & $<5$ & $<5$ & $>89$ & $>89$ \\
\hline Gemfibrozil & 344 & 9 & $<5$ & 97 & $>99$ \\
\hline Ketoprofen & 377 & $<5$ & $<5$ & $>99$ & $>99$ \\
\hline Naproxen & 443 & 10 & $<5$ & 98 & $>99$ \\
\hline Paracetamol & 114 & $<5$ & $<5$ & $>96$ & $>96$ \\
\hline primidone & 26 & $<5$ & $<5$ & $>81$ & $>81$ \\
\hline Simazine & 80 & $<5$ & $<5$ & $>94$ & $>94$ \\
\hline Sulfamethoxazole & 144 & 35 & $<5$ & 76 & $>97$ \\
\hline Triclocarban & 162 & $<10$ & $<10$ & $>94$ & $>94$ \\
\hline Triclosan & 211 & $<5$ & $<5$ & $>98$ & $>98$ \\
\hline Trimethoprim & 974 & 9 & $<5$ & 99 & $>99$ \\
\hline Verapamil & 83 & $<5$ & $<5$ & $>94$ & $>94$ \\
\hline
\end{tabular}

\subsubsection{Micropollutants removal mechanisms}

The micropollutants removal data obtained for day 1 is only considered here to explain the removal mechanisms since the concentrations of all micropollutants removed at day 7 were less than the detection limit of $5-10 \mathrm{ng} / \mathrm{L}$ (Table 4). The removal mechanism of micropollutants by GAC has been generally explained by their hydrophobicity which is usually described by the octonol-water partition coefficients (Log $\mathrm{K}_{\text {owValues, }} \log$ of the ratio of concentrations of un-ionised compound between the solvents, n-octonol and water), and acid dissociation constants (pKa values) [12,14]. Log $\mathrm{K}_{\mathrm{ow}}$ can correctly determine the hydrophobicity only if the compound is unionised. For compounds which are partially ionised at the $\mathrm{pH}$ of $\mathrm{ROC}$, a correction needs to be applied to the $\log \mathrm{K}_{\mathrm{ow}}$ before it can be used as a measure of hydrophobicity. de Ridder et al. [39] and Yang et al. [34] made such a 
correction using the $\mathrm{pKa}$ values of the compounds to account for the ionic speciation of the compound at the $\mathrm{pH}$ of the wastewater using simple equations. Recently, chemical software have been used to more accurately make this correction and the corrected parameter is called $\log \mathrm{D}$ (D stands for distribution coefficient). These types of software consider the ratios of the equilibrium concentrations of all species (ionised and unionised) of a particular compound in the octonol phase and water phase. Quintanilla [40] used the software called ADME/Tox and Löwenberg et al. [15] used V9.04 for Solaris (@ 1994-2010 ACD/Labs). In this paper the latter software was utilised (Table 3). Log D > 3.0-3.2 is generally considered to indicate that the compound is significantly hydrophobic $[37,40]$.

Figure 3 presents the relationship between percentage removals of micropollutants and their respective $\log \mathrm{D}$ values. Since many of the micropollutants had effluent concentrations less than the detection limit only the data for micropollutants having absolute effluent concentrations were included in the relationship. Figure 3 illustrates that the five highly hydrophobic micropollutants (troclocarbon, triclosan, amtriptyline, clozapine, verapamil) (log D > 3.0) were almost completely removed by the MF-GAC (90-100\%). The micropollutants DEET, primidone, and sulfamethoxazole which have low hydrophobicity or are hydrophilic $(\log \mathrm{D}<3.0)$ were only removed in small amounts. Löwenberg et al. [15] also recorded that sulfamethoxazole recorded the lowest removal percentage among five micropollutants tested in a municipal wastewater treatment plant effluent using a hybrid UF/PAC treatment system. They explained the smallest removal of this micropollutant was due to its lowest $\log \mathrm{D}$ value and negative charge at the studied $\mathrm{pH}$.

There were many other micropollutants (atenolol, caffeine, ketoprofen, naproxen, paracetamol, trimethoprim, gemfibrozil, diclofenac, carbamazepine, simazine) which were less hydrophobic or hydrophilic but a high percentage of them were removed (Figure 3). Of these micropollutants, atenolol, caffeine, paracetomol, trimethoprim, gemfibrozil, 
carbamazepine, and simazine were either positively charged or had zero net charge (Table 3) and therefore they might have been removed by electrostatic adsorption to the negatively charged GAC. The micropollutants ketoprofen, naproxen, gemfibrozil, and diclofenac were hydrophilic or less hydrophobic and negatively charged. While they were expected to have low removal percentages they had in fact high removal percentages. The reason for this peculiar behaviour is not clear but it could be due to their structural characteristics which might have helped them to be removed by mechanisms other than electrostatic adsorption or hydrophobicity such as van der Waals attraction, hydrogen bonding, П- bonding, and aromaticity [15]. Nguyen et al. [41] have cited many studies where results contrary to the trend expected from hydrophobicity considerations have been reported in the literature. 


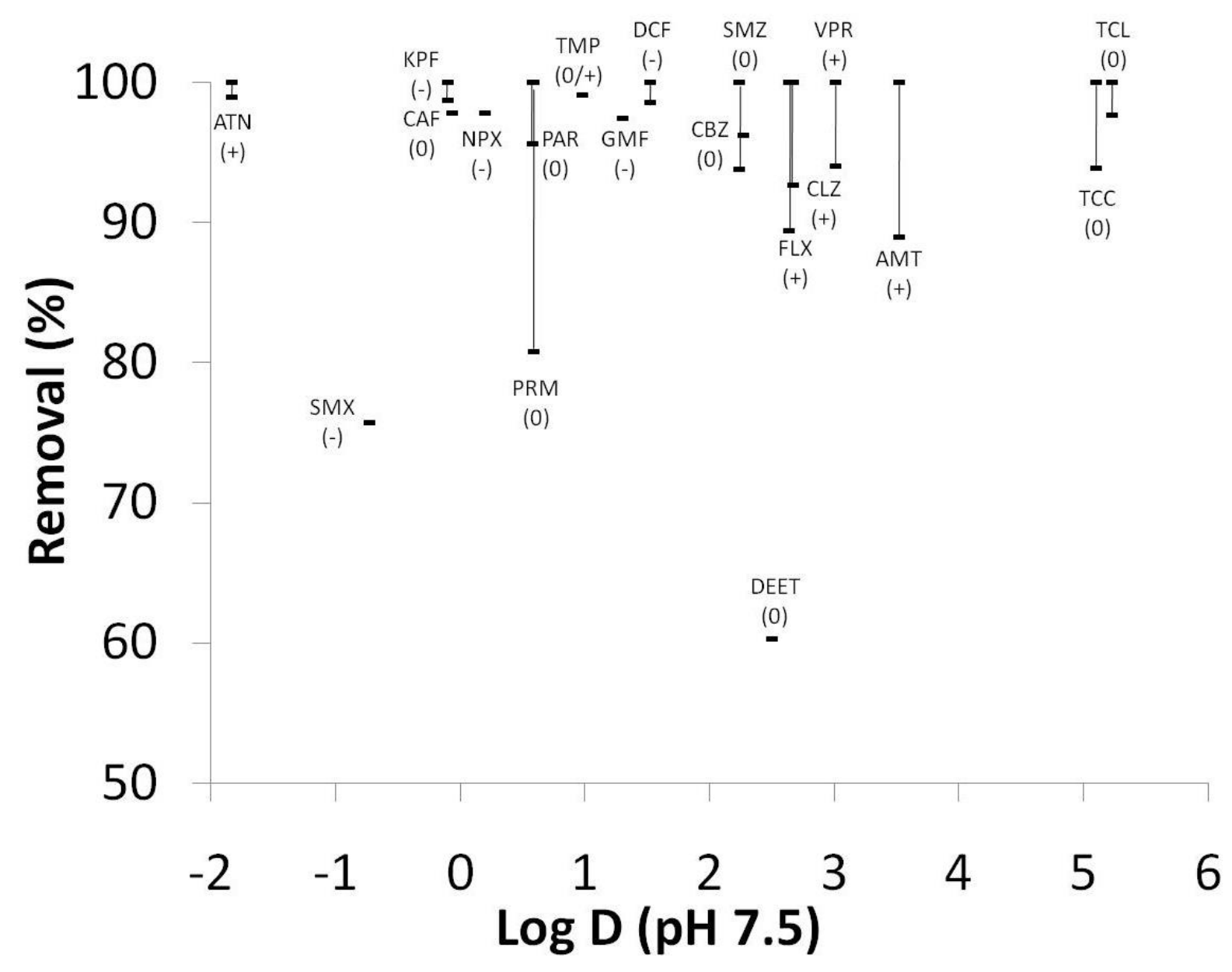

Figure 3. Removal of PPCPs by MF/GAC hybrid system from ROC as the function of calculated Log D [CAF - Caffeine; ATN - Atenolol; TMP - Trimethoprim; PAR Paracetamol; SMZ - Simazine; SMX - Sulfamethoxazole; CBZ - Carbamazepine; KPF Ketoprofen; NPX - Naproxen; CLZ - Clozapine; VPR - Verapamil; FLX - Fluoxetine; DCF - Diclofenac; GMF - Gemfibrozil; TCL - Triclosan; TCC - Triclocarbon; AMT Amtriptyline; DEET - Diethyltoluamide; PRM - Primidone]

\subsection{Practical implications}


The MF-GAC hybrid system could effectively remove the organic micropollutants and significantly reduce the organic loading in receiving waters. It is possible that a portion of the MF-GAC hybrid system effluent can be blended with RO effluent (treated water) which will provide micropollutants-free water. At the same time it can supply the necessary nutrients for agricultural application because the RO effluent does not have any nutrients while the MF-GAC will have all the nutrients in the ROC. The ROC concentrations of nutrients $(\mathrm{N}, \mathrm{P}, \mathrm{S}, \mathrm{Ca}, \mathrm{Mg}$, and $\mathrm{K}$ ) in Table 2 are expected to enhance the growth of agricultural crops as these are essential nutrients for plants. However, the $\mathrm{Na}$ and $\mathrm{Cl}$ concentrations in ROC and therefore in the MF-GAC effluent are high and they can affect the growth of plants, especially those plants which are sensitive to these elements. The effect of $\mathrm{Na}$ needs to be considered in relation to its ratio to the concentrations of $\mathrm{Ca}$ and $\mathrm{Mg}$ rather than $\mathrm{Na}$ alone. Such a ratio known as the sodium adsorption ratio [42] is approximately 4-8 in the ROC which is below the Na risk level of 14 . Therefore only $\mathrm{Cl}$ is of risk if the MF-GAC effluent is applied directly to crops. However, if one-third to half of the MF-GAC effluent is blended with the $\mathrm{RO}$ effluent the water is safe for application to crops that are $\mathrm{Cl}$ sensitive to moderately tolerant $(175-700 \mathrm{mg} / \mathrm{L})$ [42]. This will also increase the quantity of water with useful nutrients that can then be used for irrigation reuse.

Another possibility is to recycle the MF-GAC hybrid system effluent back to RO feed as this will lead to reduced organic fouling of the RO membrane due to reduced DOC in the blend. The two options are illustrated in Figure 4.

A cost calculation was made to evaluate the economics of using the SMAHS system in micropollutant removal. The amount of GAC necessary was higher for ROC $\left(270 \mathrm{~g} / \mathrm{m}^{3}\right.$ of treated water) than the amount necessary for biologically treated sewage effluent (less than $50-100 \mathrm{~g} / \mathrm{m}^{3}$ of water treated) due to the high concentration of DOC and micropollutants in 
ROC. The major cost in the SMAHS is the daily replacement of GAC. The cost of GAC to treat $1 \mathrm{~m}^{3}$ of ROC was $0.25 \mathrm{US} \$ / \mathrm{m}^{3}$. The GAC cost is taken from Nguyen et al. [43]. Considering the adverse environmental consequences of disposing of ROC into the environment, a cost figure of $0.25 \mathrm{US} \$ / \mathrm{m}^{3}$ of water treated is not high. 


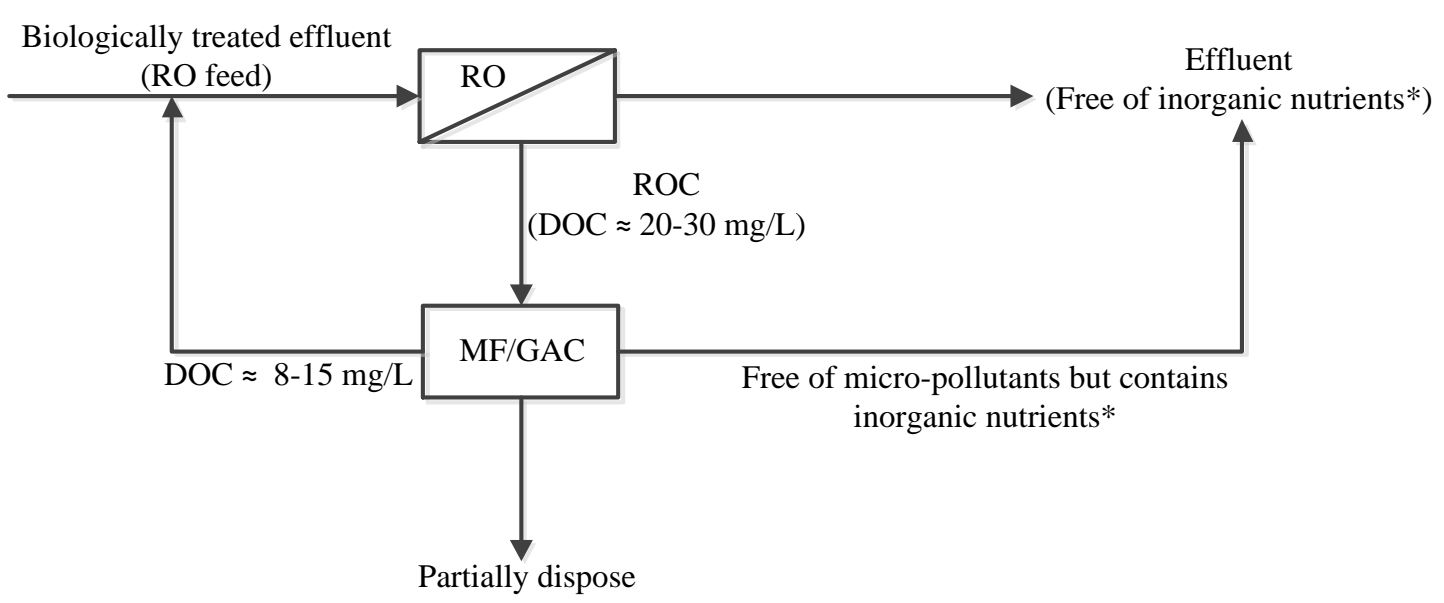

Figure 4. A proposed scheme for the beneficial use of the MF-GAC hybrid system effluent (*inorganic nutrients are $\mathrm{K}^{+}, \mathrm{Ca}^{2+}, \mathrm{Mg}^{2+}, \mathrm{NO}_{3}{ }^{-}, \mathrm{SO}_{4}{ }^{2-}, \mathrm{PO}_{4}{ }^{3-}$ )

\section{Conclusions}

The following conclusions are derived from the study:

i. 19 of the 31 micropollutants examined had concentrations above the detection limit of $5-$ $10 \mathrm{ng} / \mathrm{L}$ in which few (Verapamil, Amtriptyline and Simvastatin) exceeded or tended to exceed their respective critical environmental concentration. Some of them can also be potentially toxic to organisms when continuously exposed for a long time, especially when they are present in mixtures.

ii. Initially added $10 \mathrm{~g} / \mathrm{L}$ GAC dose with $10 \%$ daily replacement maintained DOC removal at $50-80 \%$ for $10 \mathrm{~d}$, the removal slightly decreasing over time.

iii. The five most hydrophobic micropollutants (log $\mathrm{D}>3.0$ ) were almost completely removed. Ten less hydrophobic or hydrophilic micropollutants $(\log \mathrm{D}<3.0)$ had high removal percentages, probably because they had a positive or neutral charge and therefore were electrostatically adsorbed to the negatively charged GAC. While there were few 
which were less hydrophobic or hydrophilic and had negative charges, they also had high percentage removals. Other mechanisms of adsorption might have operated for them.

\section{Acknowledgements}

This study was funded by the Cooperative Research Centre for Contamination Assessment and Remediation of the Environment (CRC-CARE) (Project Number 4.1.15.12/13). The authors would like to thank Dr Andrzej Listowski for providing the ROC.

\section{References}

[1] S.A. Snyder, S. Adham, A.M. Redding, F.S. Cannon, J. DeCarolis, J. Oppenheimer, E.C. Wert, Y. Yoon, Role of membranes and activated carbon in the removal of endocrine disruptors and pharmaceuticals, Desalination, 202 (2007) 156-181.

[2] L. Gunnarsson, A. Jauhiainen, E. Kristiansson, O. Nerman, D.G.J. Larsson, Evolutionary Conservation of Human Drug Targets in Organisms used for Environmental Risk Assessments, Environ. Sci. Technol., 42 (2007) 5807-5813.

[3] S.L. Bartelt-Hunt, D.D. Snow, T. Damon, J. Shockley, K. Hoagland, The occurrence of illicit and therapeutic pharmaceuticals in wastewater effluent and surface waters in Nebraska, Environ. Pollut., 157 (2009) 786-791.

[4] S.D. Kim, J. Cho, I.S. Kim, B.J. Vanderford, S.A. Snyder, Occurrence and removal of pharmaceuticals and endocrine disruptors in South Korean surface, drinking, and waste waters, Water Res., 41 (2007) 1013-1021. 
[5] M. Stumpf, T.A. Ternes, R.D. Wilken, R.S. Vianna, W. Baumann, Polar drug residues in sewage and natural waters in the state of Rio de Janeiro, Brazil, Science of The Total Environment, 225 (1999) 135-141.

[6] T.A. Ternes, A. Joss, H. Siegrist, Peer reviewed: scrutinizing pharmaceuticals and personal care products in wastewater treatment, Environ. Sci. Technol., 38 (2004) 392A-399A.

[7] M. Carballa, F. Omil, J.M. Lema, M.I. Llompart, C. García-Jares, I. Rodríguez, M. Gómez, T. Ternes, Behavior of pharmaceuticals, cosmetics and hormones in a sewage treatment plant, Water Res., 38 (2004) 2918-2926.

[8] P. Verlicchi, M. Al Aukidy, E. Zambello, Occurrence of pharmaceutical compounds in urban wastewater: Removal, mass load and environmental risk after a secondary treatment - A review, Sci. Total Environ., 429 (2012) 123-155.

[9] A. Göbel, A. Thomsen, C.S. McArdell, A. Joss, W. Giger, Occurrence and sorption behavior of sulfonamides, macrolides, and trimethoprim in activated sludge treatment, Environ. Sci. Technol., 39 (2005) 3981-3989.

[10] N. Bolong, A.F. Ismail, M.R. Salim, T. Matsuura, A review of the effects of emerging contaminants in wastewater and options for their removal, Desalination, 239 (2009), 229-246.

[11] A. Pal, K.Y.H. Gin, A.Y.C. Lin, M. Reinhard, Impacts of emerging organic contaminants on freshwater resources: Review of recent occurrences, sources, fate and effects, Sci. Total Environ., 408 (2010) 6062-6069.

[12] P. Westerhoff, Y. Yoon, S. Snyder, E. Wert, Fate of Endocrine-Disruptor, Pharmaceutical, and Personal Care Product Chemicals during Simulated Drinking Water Treatment Processes, Environ. Sci. Technol., 39 (2005) 6649-6663. 
[13] K.J. Choi, S.G. Kim, S.H. Kim, Removal of antibiotics by coagulation and granular activated carbon filtration, J. Hazard Mater., 151 (2008) 38-43.

[14] J. Margot, C. Kienle, A. Magnet, M. Weil, L. Rossi, L.F. de Alencastro, C. Abegglen, D. Thonney, N. Chèvre, M. Schärer, D.A. Barry, Treatment of micropollutants in municipal wastewater: Ozone or powdered activated carbon?, Sci. Total Environ., 461462 (2013) 480-498.

[15] J. Löwenberg, A. Zenker, M. Baggenstos, G. Koch, C. Kazner, T. Wintgens, Comparison of two PAC/UF processes for the removal of micropollutants from wastewater treatment plant effluent: Process performance and removal efficiency, Water Res., 56 (2014) 26-36.

[16] S. Vigneswaran, D.S. Chaudhary, H.H. Ngo, W.G. Shim, H. Moon, Application of a PAC-Membrane Hybrid System for Removal of Organics from Secondary Sewage Effluent: Experiments and Modelling, Sep. Sci. Technol., 38(2003) 2183-2199.

[17] S. Jeong, Y.J. Choi, T.V. Nguyen, S. Vigneswaran, T.M. Hwang, Submerged membrane hybrid systems as pretreatment in seawater reverse osmosis (SWRO): Optimisation and fouling mechanism determination, J. Membr. Sci., 411-412 (2012) 173-181.

[18] K.Y. Kim, H.S. Kim, J. Kim, J.W. Nam, J.M. Kim, S. Son, A hybrid microfiltrationgranular activated carbon system for water purification and wastewater reclamation/reuse, Desalination, 243 (2009) 132-144.

[19] R. Thiruvenkatachari, W. Shim, J. Lee, H. Moon, Effect of powdered activated carbon type on the performance of an adsorption-microfiltration submerged hollow fiber membrane hybrid system, Korean J. Chem. Eng., 21 (2004) 1044-1052.

[20] S. Vigneswaran, W.S. Guo, P. Smith, H.H. Ngo, Submerged membrane adsorption hybrid system (SMAHS): process control and optimization of operating parameters, Desalination, 202 (2007) 392-399. 
[21]W.S. Guo, S. Vigneswaran, H.H. Ngo, H. Chapman, Experimental investigation of adsorption-flocculation-microfiltration hybrid system in wastewater reuse, J. Membr. Sci., 242 (2004) 27-35.

[22] M.A. Johir, S. Shanmuganathan, S. Vigneswaran, J. Kandasamy, Performance of submerged membrane bioreactor (SMBR) with and without the addition of the different particle sizes of GAC as suspended medium, Bioresour. Technol., 141 (2013) 13-18.

[23] M. Pradhan, S. Vigneswaran, J. Kandasamy, R.B. Aim, Combined effect of air and mechanical scouring of membranes for fouling reduction in submerged membrane reactor, Desalination, 288 (2012) 58-65.

[24] S. Shanmuganathan, T.V. Nguyen, W.G. Shim, J. Kandasamy, S. Vigneswaran, Performance of submerged membrane - Ion exchange hybrid system with Purolite A502PS in treating reverse osmosis feed, Sep. Purif. Technol., 122 (2014) 24-31.

[25] S. Shanmuganathan, M.A.H. Johir, T.V. Nguyen, J. Kandasamy, S. Vigneswaran, Experimental evaluation of microfiltration-granular activated carbon (MF-GAC)/nano filter hybrid system in high quality water reuse, J. Membr. Sci., 476 (2015) 1-9.

[26] S. Shanmuganathan, T.V. Nguyen, S. Jeong, J. Kandasamy, S. Vigneswaran, Submerged membrane - (GAC) adsorption hybrid system in reverse osmosis concentrate treatment, Sep. Purif. Technol., 146 (2015) 8-14.

[27] W. Wang, P. Gu, G. Zhang, L. Wang, Organics removal from ROC by PAC accumulative countercurrent two-stage adsorption-MF hybrid process - A laboratoryscale study, Sep. Purif. Technol., 118 (2013) 342-349.

[28] B.J. Vanderford, S.A. Snyder, Analysis of Pharmaceuticals in Water by Isotope Dilution Liquid Chromatography/Tandem Mass Spectrometry, Environ. Sci. Technol., 40 (2007) $7312-7320$. 
[29] J. Fick, R.H. Lindberg, M. Tysklind, D.G.J. Larsson, Predicted critical environmental concentrations for 500 pharmaceuticals, Regul. Toxicol. Pharm., 58 (2010) 516-523.

[30] M. Cleuvers, Aquatic ecotoxicity of pharmaceuticals including the assessment of combination effects, Toxicol. Letters, 142(2003) 185-194.

[31] C.M. Flaherty, S.I. Dodson, Effects of pharmaceuticals on Daphnia survival, growth, and reproduction, Chemosphere, 61 (2005) 200-207.

[32] M. Cleuvers, Mixture toxicity of the anti-inflammatory drugs diclofenac, ibuprofen, naproxen, and acetylsalicylic acid, Ecotoxicol. Environ. Safe., 59 (2004) 309-315.

[33] D. Serrano, S. Suárez, J.M. Lema, F. Omil, Removal of persistent pharmaceutical micropollutants from sewage by addition of PAC in a sequential membrane bioreactor, Water Res., 45 (2011) 5323-5333.

[34] X. Yang, R.C. Flowers, H.S. Weinberg, P.C. Singer, Occurrence and removal of pharmaceuticals and personal care products (PPCPs) in an advanced wastewater reclamation plant, Water Res., 45 (2011) 5218-5228.

[35] E. Hapeshi, A. Achilleos, M.I. Vasquez, C. Michael, N.P. Xekoukoulotakis, D. Mantzavinos, D. Kassinos, Drugs degrading photocatalytically: Kinetics and mechanisms of ofloxacin and atenolol removal on titania suspensions, Water Res., 44(2010) 1737-1746.

[36] T. Loftsson, Í.B. Össurardóttir, T. Thorsteinsson, M. Duan, M. Másson, Cyclodextrin solubilization of the antibacterial agents triclosan and triclocarban: Effect of Ionization and Polymers, J. Incl. Phenom. Macro. Chem., 52 (2005) 109-117.

[37] L.N. Nguyen, F.I. Hai, J. Kang, W.E. Price, L.D. Nghiem, Coupling granular activated carbon adsorption with membrane bioreactor treatment for trace organic contaminant removal: Breakthrough behaviour of persistent and hydrophilic compounds, J. Environ. Manage., 119 (2013) 173-181. 
[38] A.M. Kennedy, R.S. Summers, Effect of DOM size on organic micropollutant adsorption by GAC, Environ. Sci. Technol., 49 (2014) 6617-6624.

[39] D.J. de Ridder, M. McConville, A.R.D. Verliefde, L.T.J. van der Aa, S.G.J. Heijman, J.Q.J.C. Verberk, L.C. Rietveld, J.C. van Dijk, Development of a predictive model to determine micropollutant removal using granular activated carbon. Drink, Water Eng. Sci. Discuss., 2 (2009) 189-204.

[40] V.A.Y. Quintanilla, Rejection of Emerging Organic Contaminants by Nanofiltration and Reverse Osmosis Membranes: Effects of Fouling, modelling and Water Reuse, CRC Press/Balkema, the Netherlands, 2010.

[41] L.N. Nguyen, F.I. Hai, J. Kang, W.E. Price, L.D. Nghiem, Removal of trace organic contaminants by a membrane bioreactor-granular activated carbon (MBR-GAC) system, Bioresour. Technol., 113 (2012) 169-173.

[42] S. Shanmuganathan, S. Vigneswaran, T.V. Nguyen, P. Loganathan, J. Kandasamy, Use of nanofiltration and reverse osmosis in reclaiming micro filtered biologically treated sewage effluent for irrigation, Desalination, 364 (2015) 119-125.

[43] T.V. Nguyen, S. Jeong, T.T.N. Pham, J. Kandasamy, S. Vigneswaran, Effect of granular activated carbon filter on the subsequent flocculation in seawater treatment, Desalination, 354 (2014) 9-16. 